\title{
Toxicological Profile of Acutely Poisoned Cases Admitted to Poison Control Center, Ain-Shams University Hospitals during Year 2013
}

\author{
Dr. Hany Tawfik ${ }^{1}$ and Dr. Hend ElHelaly ${ }^{2}$
}

\author{
${ }^{1}$ Fellow of clinical toxicology, Poison Control Center \\ ${ }^{2}$ Department of Forensic medicine and Clinical Toxicology, Faculty of Medicine \\ Ain Shams University, Cairo, Egypt.
}

\begin{abstract}
Background: Acute poisoning is a medical emergency that mandate brief analysis of the nature, severity and outcome of acute poisoning cases in order to take up appropriate planning, prevention and management techniques. The Poison Control Center Ain Shams University, Hospitals (PCCASUH) is the first established in the Middle East managed and treated more than 20474 patients during year (2013).

The aim of the study is to estimate the pattern of poisoning of cases admitted to the Poison Control Centre Ain Shams University Hospitals (PCCASUH) during year (2013). In-addition, to figure out the commonest poisoning causes, ways of management and outcomes during this year.

Patients and Methods: Clinical and Management data were obtained from medical records of cases admitted at PCCASUH during year (2013) and descriptive statistical analysis of this data was accomplished.

Results: Overall, (20474) intoxicated cases were recorded and (60.9\%) were 15 to 40 year old. Female cases were $53.9 \%$ and that was more than male cases which were $(46.1 \%)$. Children up to 15 year old represented $(31.5 \%)$ of cases. Attempts of suicide were more common $(47.1 \%)$ among cases presented while accidental exposures constituted $(45.4 \%)$ of cases. Food poisoning, organophosphates, household products and drugs of abuse were the more frequent case presentations. Cases were classified as mild cases (82.7\%), moderate cases (12.1\%) and severe cases (5.2\%) according to Person et., al. (1998). Seventy four fatalities were recorded during (2013) at PCCASUH. Management of these cases was described with (3\%) needed emergency measures.

Conclusions and Recommendations: This study revealed mortalities and morbidities presented to PCCASUH during (2013) were more than that recorded during year (2011) and (2012) as well as most of cases were suicidal attempts. This might be attributed to the security, economic and political problems affecting Egyptian community and population personality in negative way. Strict laws and regulations are needed to control the medication as well as households marketing and drugs of abuse availability.
\end{abstract}

\footnotetext{
Introduction

$\mathrm{P}$ oisoning is considered a major global health problem that mandate emergency hospitalization (Gurung et., al; 2011). Substantial differences in socioeconomic and cultural situations in different countries cause various patterns of poisoning with different poisonous agents. These differences vary from country to country and between geographical areas within the same country (Gheshlaghi et., al. 2013).
}

Special epidemiological surveillance of poisoning cases for each country is necessary to determine the problem according to which preventive measures can be taken (Andýran and Sarýkayalar, 2004). Moreover, the profile of patients with acute poisoning and their choice of agents not only depend upon the socioeconomic, religious and cultural status but also vary greatly between different countries (Singh et., al. 2011). 
Despite the continuous update of information on poisons and intoxications, several problems have yet to be resolved such as insufficient awareness regarding the potential hazards of poisons. Moreover, physicians are still not adequately trained in clinical toxicology departments, and limited availability and insufficient clinical exposure information (Hoffman, 2007).

Since the beginning of the twentieth century industrialization and technological advancement have resulted in an exponential growth in the number of chemicals introduced into the environment, workplace and home. These include medications, cleaning substances, pesticides, petroleum distillates, and drugs of abuse (Wax, 2006).

\section{Aim of the work}

This study aimed to estimate the pattern of poisoning of cases admitted to the Poison Control Centre Ain Shams University Hospitals (PCCASUH) during year 2013. Inaddition, to figure out the commonest poisoning causes, ways of management and outcomes during this year.

\section{Patients and Methods}

This is a retrospective hospital record-based study evaluating morbidity, management and outcome done to cases presented to the Poison Control Centre, Ain Shams University Hospitals (PCCASUH) during year (2013). Cases presented to PCCASUH were 20474 over a 12month period (from January 2013 to end of December 2013). Data was collected from a specially designed computerized program comprised demographic, clinical and management data. This data received was subjected to statistical analysis and tabulation. An approval was taken from the director of the PCCASUH and anonymous recording was done as well as all confidentiality issues were considered.

The clinical severity of each case was graded according to previously published criteria of Persson et al., (1998) who outline a standardized scale for poisoning severity grading that provides qualitative evaluation of morbidity, better identification of real risks and comparability of data. Grading was described as; (0): None, no symptoms or signs related to poisoning, (1): Mild, transient and spontaneously resolving symptoms, (2): Moderate, Pronounced or prolonged symptoms, and (3): Severe, or life-threatening symptoms and Death. Moreover, the study correlating the morbidity and mortality to the implicated poisoning such as pharmaceuticals, drug of abuse and other offending agents which included, food poisoning, chemicals, natural poisoning (poisonous plants and venomous animals), gases, metals and miscellaneous agents.

\section{Results}

Table (1) showed that the majority of cases $(60.9 \%)$ were from 15 to 40 year old and $(31.5 \%)$ of cases were children up to 15 years old. However, those $>40$ years old were the least presentable age group $(7.6 \%)$ during year (2013).
Table 2 showed that the female presentation to PCCASUH during year (2013) were (53.9\%) and that was more than male presentation $(46.1 \%)$. As PCCAU is located at Ain-Shams University, Cairo, most of the cases were from the regions inside the Capital (Cairo) and that constituted $(71.4 \%)$ of cases followed by Kalioubeya $(15.7 \%)$ of cases and all other Governorates represented $(12.9 \%)$ of the cases presentations during year (2013) as shown in Table 3.

Route and mode of poisoning for the cases presented to PCCASUH during (2013) showed in Table 4 $\& 5$. The tables showed that oral route represent majority of cases $(92.6 \%)$ however other routes, inhalation, injection and skin exposures constituted $(7.4 \%)$. As regards mode of poisoning both, suicidal attempts represented $(47.1 \%)$ of cases and accidental exposures represented $(45.4 \%)$ of cases presented to PCCASUH during (2013). However, drug of abuse overdose constituted only $(7.4 \%)$ and both, criminals and therapeutic errors constituted less than (1\%) of the presented cases.

In-addition, Table 6, 7 and 8 showed the offending agents frequently presented to PCCASUH during (2013). Poisoning from pharmaceuticals and drug of abuse constituted $(53.6 \%)$ of presented cases which was more than that of other implicated agents (46.4\%). The tables also showed that drug of abuse (tramadol, cannabis, opiate and benzodiazepines) constituted $(10.8 \%)$. Antiepilepleptics, antidepressants and other psychotropics constituted (6\%) of cases. Acute analgesics intoxications represented $(7.6 \%)$ of cases and that included (paracetamol, NSAIDs and salicylate) during (2013). Cardiovascular drugs presentation were (5.5\%) and theophylline was the commonest (2.9\%) offending drug. Antibiotics, other miscellaneous, unknown and over the counter as antihistaminic were constituted $(23.7 \%)$ of drug offending agents among cases presented to PCCASUH during (2013). Cases presented with food poisoning were $(15.88 \%)$ and insecticides presentations were (12.5\%), which constituted about one third of non-drug exposure (28.3\%). House-hold exposures as detergents constituted (11\%) of presented cases, however carbon monoxide (CO) poisoned cases were (2.4\%). Animal poisoning exposure constituted $(2.7 \%)$ of cases and that included scorpion and snake envenomation. Acute Alcohols poisonings represented $(1.5 \%)$ of cases and metals poisoning constituted only $(0.11 \%)$ of presented cases.

According to Persson et a., (1998), most of intoxicated cases $(82.7 \%)$ presented PCCASUH at year (2013) were graded into mild degree while, moderate degree cases constituted $(12.1 \%)$ of cases and severe cases were only (5.2\%) as shown in Table (9). Moreover, Table 10 revealed that there were (74) cases died as a complication of intoxications most of them died from organophsphorus intoxications $(40.5 \%)$ while deaths from tramadol were (20\%). Deaths from Carbon monoxides and Phosphides represented as (5.4\%) of died cases equally. Table 11 revealed that most of the cases 
$(82.7 \%)$ presented to PCCASUH at year (2013) were observed for only 6 hours. However, (12.5\%) of cases admitted to PCCASUH for one day and the rest of cases $(4.1 \%)$ were admitted for $>$ one day to four days, those admitted five days to whole week were only $(0.7 \%)$ of presented cases.

Measures were done to presented cases were described in Tables 12 and 13 which showed that emergency first aid measures were delivered to $(3 \%)$ of all presented cases during year (2013) and (45.6\%) of them needed endotracheal intubation. In-addition,
$(37.3 \%)$ of those cases mandated mechanical ventilation and $(17.1 \%)$ of them needed dopamine infusion. Moreover, Table 13 showed stomach and skin decontaminations measures that were done for $(8.7 \%)$ of presented cases. Enhanced elimination as hemodialysis and MDAC were done to $(9.6 \%)$ of cases. In-addition, atropine and obidoxime were the most common antidote used followed by snake and scorpion antivenin, followed by N-Acetyl Cysteine (NAC ) administration in paracetamol intoxicate cases.

Table 1: Age distribution of poisoned cases received in PCCASUH through year 2013

\begin{tabular}{|l|l|l|}
\hline Age/ (year) & \multicolumn{1}{|c|}{ No } & \multicolumn{1}{c|}{$\boldsymbol{~}$} \\
\hline$<7$ & 5200 & 25.4 \\
\hline $7-<15$ & 1249 & 6.1 \\
\hline $15-<25$ & 7494 & 36.6 \\
\hline $25-40$ & 4975 & 24.3 \\
\hline$>40$ & 1556 & 7.6 \\
\hline Total & 20474 & \\
\hline
\end{tabular}

Table 2: Sex distribution of poisoned cases received in PCCASUH through year 2013

\begin{tabular}{|l|l|l|}
\hline Sex & No & \% \\
\hline Female & 11035 & 53.9 \\
\hline Male & 9439 & 46.1 \\
\hline total & 20474 & \\
\hline
\end{tabular}

Table 3: Residence distribution of poisoned cases received in PCCASUH through year 2013

\begin{tabular}{|l|l|l|}
\hline \multicolumn{1}{|c|}{ Region } & \multicolumn{1}{c|}{ No } & \multicolumn{1}{c|}{$\%$} \\
\hline Cairo & 14618 & 71.4 \\
\hline Kalioubeya & 3214 & 15.7 \\
\hline Giza & 1925 & 9.4 \\
\hline Other Delta Governorates & 225 & 1.1 \\
\hline Upper Egypt Governorates & 369 & 1.8 \\
\hline Suez Canal Governorates & 123 & 0.6 \\
\hline Total & 20474 & \\
\hline
\end{tabular}

Table 4: Routes of poisoning of poisoned cases received in PCCASUH through year 2013

\begin{tabular}{|l|l|l|}
\hline \multicolumn{1}{|c|}{ Route } & \multicolumn{1}{c|}{ No } & \multicolumn{1}{c|}{$\%$} \\
\hline Ingestion / Oral & 18965 & 92.63 \\
\hline Inhalation / nasal & 530 & 2.59 \\
\hline Bite / sting & 539 & 2.63 \\
\hline Dermal / skin-scalp & 430 & 2.1 \\
\hline Injection & 10 & 0.05 \\
\hline Total & 20474 & \\
\hline
\end{tabular}


Table 5: Mode of poisoning of poisoned cases received in PCCASUH through year 2013

\begin{tabular}{|l|l|l|}
\hline \multicolumn{1}{|c|}{ Mode } & \multicolumn{1}{c|}{ No } & \multicolumn{1}{c|}{$\%$} \\
\hline Suicidal & 9641 & 47.09 \\
\hline Accidental & 9295 & 45.4 \\
\hline Overdose drug of abuse & 1515 & 7.4 \\
\hline Criminal & 13 & 0.06 \\
\hline Therapeutic error & 10 & 0.05 \\
\hline Total & 20474 & \\
\hline
\end{tabular}

Table 6: Type of causative agents of poisoned cases received in PCCASUH through year 2013

\begin{tabular}{|l|l|c|}
\hline \multicolumn{1}{|c|}{ Type } & \multicolumn{1}{c|}{ No } & \% \\
\hline Pharmaceuticals and Drugs of Abuse & 10974 & 53.6 \\
\hline Other offending agents and miscellaneous & 9500 & 46.4 \\
\hline Total & 20474 & \\
\hline
\end{tabular}

Table 7: Pharmaceuticals and drug of abuse intoxicated cases received in PCCASUH through year 2013

\begin{tabular}{|c|c|c|}
\hline Drug & No & $\%$ \\
\hline \multicolumn{3}{|l|}{ Drugs of Abuse $10.9 \%$} \\
\hline Tramadol & 1412 & 6.9 \\
\hline Benzodiazepine & 430 & 2.1 \\
\hline Cannabis & 266 & 1.3 \\
\hline Opiate & 102 & 0.5 \\
\hline \multicolumn{3}{|l|}{ Centrally acting drugs $6.1 \%$} \\
\hline Carbamazepine & 328 & 1.6 \\
\hline Psychotropics & 328 & 1.6 \\
\hline Other antiepileptics & 61 & 0.3 \\
\hline anticholinergic & 41 & 0.2 \\
\hline Tricyclic Antidepressants (TCA) & 471 & 2.3 \\
\hline \multicolumn{3}{|l|}{ Analgesics $7.6 \%$} \\
\hline Paracetamol + cold Medications & 491 & 2.4 \\
\hline Non-steroidal Anti-inflammatory drugs (NSAIDs) & 901 & 4.4 \\
\hline Salicylate & 164 & 0.8 \\
\hline \multicolumn{3}{|l|}{ Cardiovascular drugs $5.5 \%$} \\
\hline Theophylline & 594 & 2.9 \\
\hline Antihypertensive & 225 & 1.1 \\
\hline Digoxin & 82 & 0.4 \\
\hline Beta Blockers & 205 & 1 \\
\hline Calcium Channel Blockers (CCB) & 20 & 0.1 \\
\hline \multicolumn{3}{|l|}{ Anti-diabetic medications $1.6 \%$} \\
\hline Insulin + OHG (Oral Hypoglycemic) & 328 & 1.6 \\
\hline \multicolumn{3}{|l|}{ Other implicated agents $22.1 \%$} \\
\hline Antibiotics & 1106 & 5.4 \\
\hline Flagyl & 184 & 0.9 \\
\hline Antihistaminics & 205 & 1 \\
\hline Vitamins & 143 & 0.7 \\
\hline Oral Contraceptive Pills (OCP) & 348 & 1.7 \\
\hline Miscellaneous & 266 & 1.3 \\
\hline Unknown drug & 2273 & 11.1 \\
\hline Total & 10974 & $\mathbf{5 3 . 6}$ \\
\hline
\end{tabular}


Table 8: Other offending agents induced intoxications among cases received in PCCASUH through year 2013

\begin{tabular}{|c|c|c|}
\hline Type & No & $(\%)$ \\
\hline \multicolumn{3}{|c|}{ Food poisoning $15.88 \%$} \\
\hline Bacterial & 3234 & 15.8 \\
\hline Ciguatera & 13 & 0.06 \\
\hline Botulism & 5 & 0.02 \\
\hline \multicolumn{3}{|c|}{ Insecticide \& rodenticide $12.5 \%$} \\
\hline Organophosphate insecticide & 2149 & 10.5 \\
\hline Zinc and aluminium Phosphide & 410 & 2 \\
\hline \multicolumn{3}{|l|}{ Detergents $11 \%$} \\
\hline Corrosives & 1412 & 6.9 \\
\hline Detergents & 328 & 1.6 \\
\hline Kerosene and petroleum. distillate & 389 & 1.9 \\
\hline Phenol & 123 & 0.6 \\
\hline \multicolumn{3}{|l|}{ Animal poisoning $2.7 \%$} \\
\hline Scorpion & 348 & 1.7 \\
\hline Snake & 205 & 1 \\
\hline Carbon Monoxide (CO) $2.4 \%$ & 491 & 2.4 \\
\hline \multicolumn{3}{|l|}{ Alcohol $1.5 \%$} \\
\hline Ethanol & 287 & 1.4 \\
\hline Methanol & 20 & 0.1 \\
\hline \multicolumn{3}{|l|}{ Metals $0.11 \%$} \\
\hline Iron & 13 & 0.06 \\
\hline Lead & 2 & 0.01 \\
\hline Mercury & 8 & 0.04 \\
\hline Plants and herbals+ Mushroom & 18 & 0.09 \\
\hline Hydrogen sulphide & 16 & 0.08 \\
\hline Paraphenylenediamine dye & 14 & 0.07 \\
\hline Lachrymatory agent (Riot control) & 13 & 0.06 \\
\hline Cyanide & 2 & 0.01 \\
\hline Total & 9500 & 46.4 \\
\hline
\end{tabular}

Table 9: Severity grading of poisoning cases received in PCCASUH through year 2013 according to Persson et al., (1998):

\begin{tabular}{|l|l|l|}
\hline Degree of severity & No & $(\mathbf{\% )}$ \\
\hline Mild & 16932 & 82.7 \\
\hline Moderate & 2477 & 12.1 \\
\hline Severe & 1065 & 5.2 \\
\hline Total & 20474 & 100 \\
\hline
\end{tabular}

Table 10: Death-related offending agents of cases received in PCCASUH through year 2013

\begin{tabular}{|l|l|l|l|l|l|}
\hline Agent & No & $\mathbf{\%}$ & Agent & No & $\%$ \\
\hline Organophosporus (OP) & $30-$ & 40.5 & Hydrogen Sulphide (H2S) & 1 & 1.4 \\
\hline Tramadol & $15-$ & 20 & Methanol & 1 & 1.4 \\
\hline Carbon Monoxide (CO) & $4-$ & 5.4 & Corrosive & 1 & 1.4 \\
\hline Zinc Phosphide & $4-$ & 5.4 & Benzodiazepines & 1 & 1.4 \\
\hline Aluminum Phosphide & $2-$ & 2.7 & Snake & 1 & 1.4 \\
\hline Kerosene & $2-$ & 2.7 & Parapphenyldiamine (PPD) & 1 & 1.4 \\
\hline Digoxin & $2-$ & 2.7 & Neuroleptics & 1 & 1.4 \\
\hline Dormex & $2-$ & 2.7 & Cyanide & 1 & 1.4 \\
\hline Opiate & $1-$ & 1.4 & Unknown poison & $4-$ & 5.4 \\
\hline Total & 74 & & & & \\
\hline
\end{tabular}


Table 11: Period of hospitalization of poisoned cases received in PCCASUH through year 2013

\begin{tabular}{|l|l|l|l|l|l|}
\hline Period of hosp. & No & $\mathbf{( \% )}$ & Period of hosp. & No & $(\boldsymbol{\%})$ \\
\hline$<6 \mathrm{~h}$ & 16932 & 82.7 & $>4-5 \mathrm{~d}$ & 35 & 0.17 \\
\hline $6 \mathrm{~h}-24 \mathrm{~h}$ & 2559 & 12.5 & $>5-6 \mathrm{~d}$ & 13 & 0.06 \\
\hline$>1 \mathrm{~d}-2 \mathrm{~d}$ & 573 & 2.8 & $>6-7 \mathrm{~d}$ & 14 & 0.07 \\
\hline$>2 \mathrm{~d}-3 \mathrm{~d}$ & 184 & 0.9 & $>7 \mathrm{~d}$ & 82 & 0.4 \\
\hline$>3 \mathrm{~d}-4 \mathrm{~d}$ & 82 & 0.4 & & & \\
\hline Total & & 20474 & 100 \\
\hline
\end{tabular}

Table 12: Emergency Treatment offered to acutely poisoned cases received in PCCASUH through year 2013

\begin{tabular}{|l|l|l|}
\hline Type of intervention & NO out from 20474 & \% \\
\hline Endotracheal intubation & 285 & 1.4 \\
\hline Mechanical Ventilation & 233 & 1.1 \\
\hline Dopamine & 107 & 0.5 \\
\hline Total & 625 & 3 \\
\hline
\end{tabular}

Table 13: Interventions offered to acutely poisoned cases received in PCCASUH through year 2013

\begin{tabular}{|c|c|c|}
\hline Type of intervention & No from total 20474 & $\%$ \\
\hline \multicolumn{3}{|l|}{ Decontamination } \\
\hline Ipecac Emesis & 1591 & 7.8 \\
\hline Gastric lavage & 171 & 0.8 \\
\hline Skin wash & 25 & 0.1 \\
\hline total & 1787 & 8.7 \\
\hline \multicolumn{3}{|l|}{ Enhanced elimination } \\
\hline MDAC & 1960 & 9.5 \\
\hline Hemodialysis & 16 & 0.08 \\
\hline Total & 1976 & 9.6 \\
\hline Antidote & no of ampoule & \\
\hline Atropine & 12578 & \\
\hline Obidoxime & 834 & \\
\hline Naloxone & 16 & \\
\hline $\mathrm{N}$-acetylcysteine & 40 & \\
\hline Scorpion anti-venoms & 61 & \\
\hline Snake anti-venoms & 274 & \\
\hline Flumazenil & 7 & \\
\hline Calcium gluconate & 12 & \\
\hline Glucagon & 12 & \\
\hline antibotulinum & 10 & \\
\hline Methylene Blue & 8 & \\
\hline Hyperbaric $\mathrm{O} 2$ therapy & 30 cases & \\
\hline Ethanol & 4 cases & \\
\hline Dextrose 25\% & 24 cases & \\
\hline
\end{tabular}

MDAC $=$ Multiple dose Activated charcoal

\section{Discussion}

Unintentional and intentional toxicological exposures continue to be a significant cause of morbidity and mortality in Egypt. PCCASUH is the first established and largest National Poison Control Center in Egypt received large number of poisoned patients yearly. During (2013), PCCASUH managed and treated (20474) cases and that was more than recorded cases during (2012) which were (19744) cases (Halawa et., al. 2013). This later data could be explained during (2013) the community instability in Egypt resulted in increased cases of suicidal attempts as well as increased drug abuse overdoes. The study revealed that the majority of cases $(60.9 \%)$ were from 15 to 40 year old and $(31.5 \%)$ of cases were children up to 15 years old. Moreover, those $>40$ year old were the least presentable age group cases $(7.6 \%)$ during 2013. This was in accordance with that recorded during 2004 to 2005 at China Emergency hospitals where the age groups between 15-34 years were the highest presentable age group (Zhou et., al. 2005). 
Comparison to other Arabic and Western countries revealed that, the greater majority of poisoning cases usually lie in the age group below 6 years of age. That was evident in the study of Moazzam et., al. (2004) at Kingdom of Saudi Arabia, who reported cases of acute chemical poisoning during the first six months of (2004), they showed that, the highest proportion of poisoned cases were observed among children $\leq 5$ years of age. Inaddition, (2011) annual report of the American Association of Poison Control Centers revealed that children under age of 6 represent up to $49 \%$ of all poison exposures (Bronstein et al., 2012).

El Masry and Tawfik (2013), stated that the high incidence of poisoning in the early adulthood and middle age deserve particular attention. This poisoning prone age group is subject to tremendous emotional and economic challenges in Egypt.

This study also showed that female presentation to PCCASUH was $(53.9 \%)$ which was more than that of male presentation $(46.1 \%)$ during year (2013).This goes parallel with, Satar, and Seydaoglu (2005) study who reported (2229) poisoned cases out of them; (32.5\%) were male and that was less than female presentation (67.5) during 1997 to 2002 at Department of Emergency Medicine, Cukurova University School of Medicine, Balcali, and Adana, Turkey. This was also shown at Rhodes et., al. (2008) report, who stated that, female presentations were more often than male and that, occurred in most agent-groups during 2001 and 2002 in annual report of Ontario, Canada Poison control center.

In Riyad teaching hospital the percentage of females who took two or more toxins was almost double than those observed among males (Al-Barraq and Farahat, 2011). This was also in accordance with what was reported during 2010-2011 in Mangalore, South India who showed that cases were observed to be higher in females than males (Ram et., al. 2014).

The increased female presentations could be explained as they are more vulnerable to psychological and emotional instabilities and that was proved that most of suicidal attempts among cases during (2013) were female.

As PCCASUH is located at Ain-Shams University, Cairo, most of the cases were from the Capital (Cairo) and that was represented as (71.4\%) of cases followed by Kalioubeya (15.7\%) and all other Governorates constituted (12.9\%) of the cases presented during year (2013).This distribution was similar to data recorded during year (2012) which revealed that most of cases came from urban areas $(70 \%)$. This was attributed to the proximity of these areas to the PCCASUH and not to the higher magnitude of the poisoning health problem (Halawa et., al. 2013).

In-contrary Guntheti, and Singh, (2011) found that rural areas presentation were $(71.51 \%)$ and that was more than urban presentation $(28.48 \%)$ in Khammam Emergency Hospitals, India. urban area.

Oral route represented majority of cases $(92.6 \%)$ admitted to PCCASUH during (2013) and other routes, inhalation, injection and skin exposures constituted (7.4 $\%$ ) of cases presentations. This goes hand in hand with Al-Barraq and Farahat, (2011) study in Riyadh teaching hospital who found that oral route was the most common route of poisoning of reported toxicity cases with increased potential for suicidal attempts. American Association of Poison Control Centers found that the oral route was the most common route of poisoning $(79.5 \%)$ during year 2010 (Alvin et., al. 2011).

This study also showed that, suicidal attempts were recorded in $(47 \%)$ of cases as well as accidental presentations were recorded in $(45.4 \%)$ of cases and that were the most common mode of poisoning among cases presented to PCCASUH during year (2013). However drug of abuse overdose constituted (7.4\%) this again could be attributed to the community problems regarding security instability during this year and availability of illicit drug of abuse. Both, homicidal and therapeutic errors constituted less than $1 \%$ of the presented cases. This was in accordance with Halawa et., al. (2013) who revealed that cases attempted suicide were (49.5\%) exceeded that of accidental $(40.6 \%)$ poisoning exposures during year (2012). Moreover, they reported that, most of attempted suicide was induced by females $(74.4 \%)$ and that was higher (69\%) among age group 15-25 year old. Suicidal poisoning was the observed etiology in the majority of poisoned cases (76.4\%) during 1997 to 2002 in Department of Emergency Medicine, Cukurova University School of Medicine, Balcali, and Adana, Turkey as reposted in the study of Satar and Seydaoglu, (2005).

In contrary, the American Association of PCCs found that only $(15.8 \%)$ of poisoning was intentional in their study report 2010. Bronstein et., al. (2012) stated that despite the strong religious morals in Islam and Christianity which ban self-destruction and deliberate self-killing, yet young adults seem not to be immune to the attempted suicide.

In-addition, this study reported that, children of preschool age (<7years) particularly male, were subjected to accidental poisoning in $(55 \%)$, this can be attributed to the particular behavior of that age group as curiosity, oral identification, discrimination inability and taste and smell immaturity. These results were similar to those of Andiran and Sarikayalar, (2004) who found that accidental poisoning was commonest amongst children and remains a significant problem for this age group in Turkey.

This study also recorded that, the poisoning resulted from pharmaceuticals, drug of abuse and over the counter medications constituted $(53.6 \%)$ and that was more than that of other implicated agents which was (46.4\%). Comparison to what had been investigated during year 2011 and 2012 revealed that (56.3\%) of poisoning presentations were due to pharmaceuticals and medications. While other offending agent's presentations account for $(43.7 \%)$ of cases (Halawa et., al. 2013 \& El Masry and Tawfik, 2013). 
Moreover, this study showed that, drug of abuse poisoning (tramadol, cannabis, opiate and benzodiazepines) constituted (10.8\%) of presentations. However, antiepilepleptics, antidepressants and other psychotropics were constituted (6\%). Acute analgesics intoxicated cases presentations were noted in $(7.6 \%)$ of cases and that included paracetamol, NSAIDs and salicylate. Cardiovascular drugs presentation were $(5.5 \%)$ and theophylline was the commonest. Other miscellaneous, unknown and over the counter medications as antihistaminic were $(32.7 \%)$ of drug offending agents. This was in agreement with poisoning pattern of cases admitted to PCCASUH during (2011)which revealed that, the medications most frequently presented were antianxiety drugs, analgesics antipyretic, antirheumatic drugs and antipsychotic drugs (El Masry and Tawfik, 2013). This could be attributed to the availability of medications in the market without restriction rules and banning programs enrolled by the government.

In-addition, food poisoning presentations were $(15.88 \%)$ and insecticides poisoned cases were $(12.5 \%)$ and that constituted about one third of other implicated agents exposures $(28.3 \%)$. House hold exposures as detergents constituted $(11 \%)$ however $\mathrm{CO}$ exposure was noted in $(2.4 \%)$ of cases and animal poisoning exposure was observed in $(2.7 \%)$ of cases. The high incidence of household products intoxications such as pesticides, kerosene and corrosive materials due to the availability at the commercial market with high concentration ingredients without safety manufacturing measures.

Satar and Seydaoglu (2005) in Turkey reported that pharmaceutical medications ingestions were the most frequent means of poisoning $(59.0 \%)$, followed by pesticides $(19.0 \%)$. They added that, the rate of poisoning with multiple drugs has declined over time, whereas the rate owing to psychoactive drugs has increased markedly.

In-contrary, the American profile of poisoning during year (2011) in the United States reported that, the most frequently offending agents involved in all human exposures were analgesics (11.7\%), cosmetics/personal care products were $(8.0 \%)$, household cleaning substances were (7.0\%), sedatives/hypnotics/antipsychotics were (6.1\%), and foreign bodies/toys/miscellaneous were (4.1\%) (Bronstein et., al. 2012). While in Turkey Dulger et.,al. (2012) reported that, Central nervous system drugs constituted (21.8\%), carbamates were (17.1\%), analgesics were (10.3\%) and organophosphorus components were (10\%) among intoxicated patients.

According to Persson et al., 1998, this study showed that, most of intoxicated cases $(82.7 \%)$ presented PCCASUH during (2013) were mild, while moderate cases were $(12.1 \%)$ and severe cases were $(5.2 \%)$. Inaddition the study revealed that there were $74(0.36 \%)$ of cases died as a complication of intoxications. Moreover, the data revealed that $(40.5 \%)$ of deaths was due to organophosphorus poisoning and (20\%) was due to tramadol overdose while carbon monoxides and phosphides were (5.4\%) equally.

This could be attributed to the increased number of case presentations with complication during (2013) especially those attempted suicide and drug abuse overdose. That was also could be explained by the availability of drug abuse as well as the unavailability of their antidotes.

Moazzam et., al. (2004) reported mortality rate was $2.2 \%$ among poisoned cases, presented during 1999 2003 at kingdom of Saudi Arabia. Shadnia, (2007) found that mortality rate of acute intoxicated cases presented to Tehran poison control center during (2003) was $1.3 \%$. Moreover, the 2011 annual report of the American Association of PCCs revealed that out of 2,334,004cases, they had 2,765 deaths (0.118\%) (Bronstein et., al. 2012). As stated by Kanchan and Menezes (2008), Poisoning with pesticides, especially those containing organophosphoru, has been associated with increased risk of mortality.

As regards hospital period of stay, this work declared that most of the cases $(82.7 \%)$ presented to PCCASUH during (2013) were admitted for only six hours. However, (12.5\%) of cases admitted up to 24 hours and the rest about $(4.1 \%)$ were admitted for more than one day to four days. This could be explained as, some of the critically ill patients afraid of being notified to police authority as routinely done at PCCASUH for any poisoned case presented to ER unit. Moreover, poor patients got discharged against medical advice owing to financial reasons as well. This was in agreement with Jalali et. al., (2012) reported that, those who observed and did not need admission were $82.8 \%$ of cases while those admitted was $13.1 \%$ of the cases. Poisoning induced comorbidities mandate longer admission were $2.7 \%$ of the cases.

Comparing to what to Paudyal, (2005) reported in Patan hospital in central of Nepal who found that, the mean hospital stay for all type of poisoning was 7.5 days. $\mathrm{He}$ added that majority of cases needed more hospital stay were organophosphorus, for 2.5 days followed by paracetamol for 2 days, and 1.5 days each for zinc phosphide and kerosene ingestion. They attributed this to intensive care unit (ICU) admission was required and almost $25 \%$ of cases developed complications.

The longer hospital stay admission was explained by Anthony and Kulkarni. (2012) who postulated that, duration of hospital stay, ventilator requirement depends on to nature and the quantity of poison, comorbid conditions, clinical complications which constituted the major determinants of outcomes in patients with poisoning.

Treatment measures that were given to cases presented to PCCASUH during (2013) were recorded in this study. Emergency treatment was delivered to (3\%) of cases with $(45.6 \%)$ of them needed endotracheal intubation, $(37.3 \%)$ of those cases mandated mechanical ventilation and $(17 \%)$ needed dopamine infusion. Other measures as stomach and skin decontamination were 
done for $(8.7 \%)$ of cases. Hemodialysis and MDAC were done to $(9.6 \%)$ of cases. In-addition, atropine and obidoxime were the most common antidote used followed by snake, scorpion antivenin and NAC. Similarly Halawa et. al., (2013) found that decontamination procedures and activated charcoal were the most frequent procedures undertaken for poisoning cases with antidotes administration followed in frequency of use as recorded from files of patients admitted to PCCASUH during year (2012). They added that, the most frequently used antidote was atropine and obidoxime reflecting the large number of received organophosphate poisoning cases. Mechanical ventilation was a common tool in ICU admitted serious cases (30\%) of which were due to organophosphrous poisoning and $17.3 \%$ due to tramadol overdose reflecting the severity grade of these types of poisoning. Ramesha et., al. (2009) stated that the first aid given with considerable value among poisoned cases admitted to medical institution in Karnataka, India was gastrointestinal lavage, dosage schedule of various antidotes such as atropine and antisnake venom.

\section{Conclusion}

This study revealed that the cases presented to PCCASUH with more mortalities and morbidities during (2013) than that recorded during year (2011) and (2012) as well as most of cases were suicidal attempts. Moreover, it was reported that drug of abuse overdose presentations were more than that presented in the year before. This data might be attributed to what the Egyptian community suffered from as security, economic and political problems which affected the Egyptian population personality in negative way during (2013). Security instabilities implicated the increased number of drug of abuse overdose and hence increased number of deaths especially unavailability of specific antidotes increased the magnitude of this problem.

\section{Recommendation}

A new governmental policy is needed to control the medication marketing.

Strict regulations for the households and insecticide free availability.

Education programs for the community about proper storage of medications and households.

Laws to strict the sale of commonly abused drugs without proper prescription of a qualified doctor should be implemented.

\section{References}

Al-Barraq A. and Farahat F. (2011): "Pattern and determinants of poisoning in a teaching hospital in Riyadh, Saudi Arabia”. Saudi Pharmaceutical Journal; 19, 57-63.

Alvin C, Daniel A, Louis R et al., (2011): “2010 Annual Report of the American Association of Poison Control Centers' National Poison Data System (NPDS): 28th Annual Report". Clinical Toxicology; 49, 910-941

Andiran N and Sarikayalar F (2004): "Pattern of acute poisonings in childhood in Ankara, what has changed in 20 years?" Turkish Journal of Pediatrics, 46(2):147-52.

Andýran N. and Sarýkayalar F. (2004): "Pattern of acute poisonings in childhood in Ankara: what has changed in twenty years?" The Turkish Journal of Pediatrics; 46: 147-152. Original Department of Pediatrics, Hacettepe University Faculty of Medicine, Ankara, Turkey.

AnthonyL., and KulkarniC. (2012): "Patterns of poisoning and drug overdosage and their outcome among in-patients admitted to the emergency medicine department of a tertiary care hospital". Indian J Crit Care Med; 16(3): $130-135$.

Bronstein A.C. Spyker D.A. Cantilena L.R. et. al., (2012): "2011Annual Report of the American Association of Poison Control Centers' National Poison Data System (NPDS), 29th Annual Report". Clinical Toxicology; 50, 911-1164

Dulger AC, Karadas S, Gonullu H, et. al., (2012) Analyses of Etiologic and Sociodemografic Properties of the Intoxicated Cases in Van City and its Environs. J Clinic Toxicol2:119.

El MasryM.K., and Tawfik H. M. (2013): “2011 Annual Report of the Poison Control Centre of Ain Shams University Hospital, Cairo, Egypt". Ain Shams Journal of Forensic Medicine and Clinical Toxicology; 20: 10-17

Gheshlaghi F, Reza M, Ardakani P, et. al., (2013): "Acute Poisoning in Children; a Population Study in Isfahan, Iran, 2008-2010". Iran J. Pediatr; 22; p: 189-193.

Guntheti B.K., and Singh U.P. (2011): "The Pattern of Poisoning in Khammam". J Indian Acad Forensic Med, Vol. 33, No. 4.

Gurung CK1, Dahal R, Khanal P, et. al., (2011): "Pattern of poisoning cases in a hospital in a Terai district of central Nepal". Nepal Med Coll J; 13(3):160-3.

Halawa H. M., Nageeb S.A., Mahmoud Kh et. al., (2013): "Annual Report of the Poison Control Centre, Ain Shams University Hospitals -Cairo, Egypt, 2012". Ain Shams Journal of Forensic Medicine and Clin toxicol; Vol. 21:27-34

Hoffman R (2007): Understanding the limitations of retrospective analyses of poison center data. ClinToxicol ; 45(8):943-5.

Jalali A.1, 3 *, Savari M. 1, S Dehdardargahi S2, and Azarpanah A1. (2012): "The Pattern of Poisoning in Southwestern Region of Iran: Envenoming as the Major Cause". Jundishapur J Nat Pharm Prod;7(3):100-105.

Kanchan T and Menezes RG (2008): Suicidal poisoning in Southern India: Gender differences. J Forensic Leg Med; 15: 7-14.

Moazzam M, Al-Saigul A, Naguib M, et al. (2004): "Pattern of acute poisoning in Al- Qassim region: a surveillance report from Saudi Arabia, 
1999-2003". Eastern Mediterranean Health Journal; Vol. 15,No. 4

Paudyal BP. (2005): "Poisoning: pattern and profile of admitted cases in a hospital in central Nepal". JNMA J Nepal Med Assoc; 44(159):92-6

Persson H, Sjöberg G, Haines J, et al., (1998): Poisoning severity score. Grading of acute poisoning. J ToxicolClinToxicol; 36(3):205.

Ram P, Kanchan T and Unnikrishnan B (2014): "Pattern of acute poisonings in children below 15 years--a study from Mangalore, South India". J Forensic Leg Med.; 25:26-9.

Ramesha K. N., Krishnamurthy B. H. ,1 and Kumar G. S.2 (2009): "Pattern and outcome of acute poisoning cases in a tertiary care hospital in Karnataka, India". Indian J Crit Care Med; 13(3): 152-155.

Rhodes AE, Bethell J, Spence J, et. al., (2008): “Age-sex differences in medicinal self-poisonings: a population-based study of deliberate intent and medical severity". Soc. Psychiatry Psychiatr. Epidemiol; 43(8):642-52.
Satar S and Seydaoglu G (2005): "Analysis of acute adult poisoning in a 6-year period and factors affecting the hospital stay". Adv.Ther. Mar-Apr; 22(2):137-47.

Shadnia S (2007): "Pattern of acute poisoning in TehranIran in 2003". Human \& experimental toxicology, 26(9):753-6.

Singh O, Javeri Y, Juneja D et al., 2011: "Profile and outcome of patients with acute toxicity admitted in intensive care unit: Experiences from a major corporate hospital in urban India". Indian J Anaesth; 55(4): 370-4.

Wax P (2006):" Historical principles and perspectives". In: Flomenbaum NE, Goldfrank LR, Hoffman RS, Howland MA, Lewin NA, Nelson LS, eds. Goldfrank's Toxicologic Emergencies. 8th edn. New York: McGraw-Hill: 1-17.

Zhou J1, Chen SY, Li ZJ., et. al., (2005): "Study of drug poisoning on 2612 cases in the department of emergency". Wei Sheng Yan Jiu. Jan;34(1):98100.

\section{الملخص العربي}

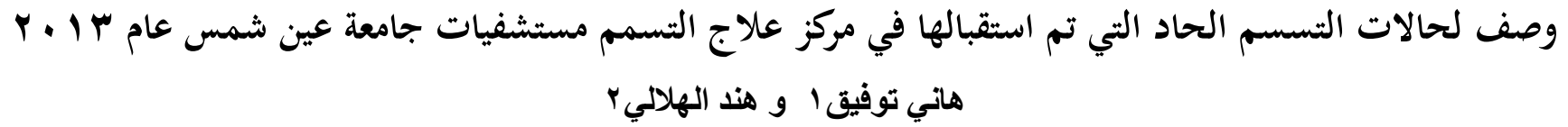

خلفية:التسمم الحاد يمثل خطورة طبية تستلزم الدراسة والتحليل وعمل ابحاث وبرامج تدريبية فعالة لتحديد الأسباب ووضع خطط لـابح للحد من

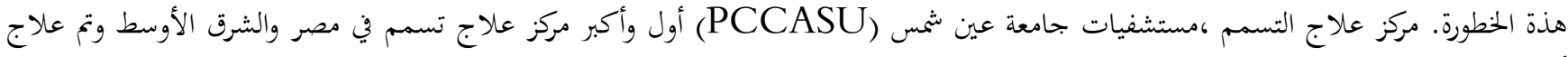

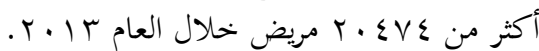

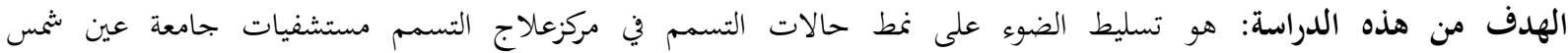

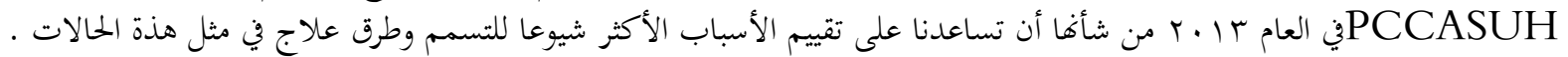

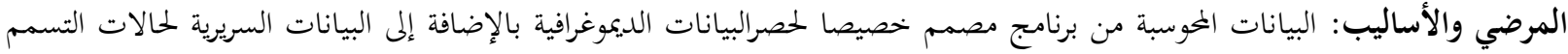
التي وردت الي PCCASUH في العام ب ا • ب . وقد تم عمل تحليل وصفي واحصائيات من السجلات الطبية وتقديمها في صورة جداول احصائية موضحة لكافة البيانات.

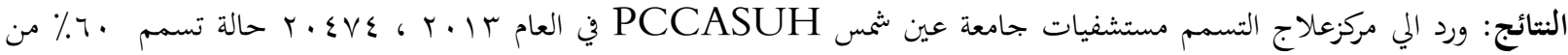

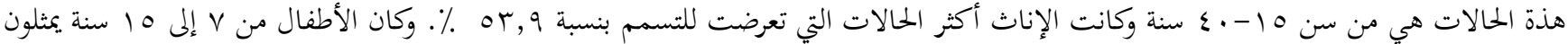

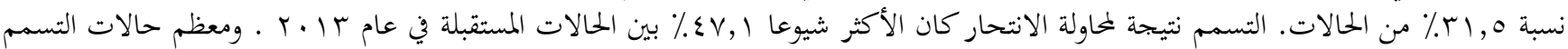

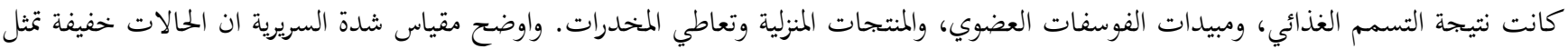

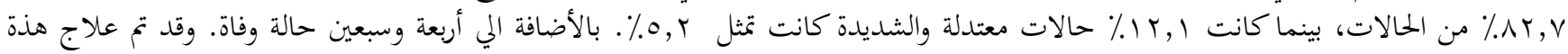

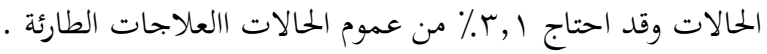

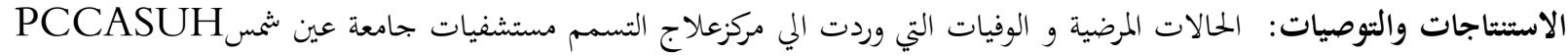

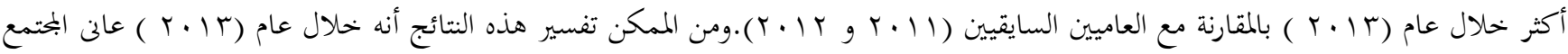

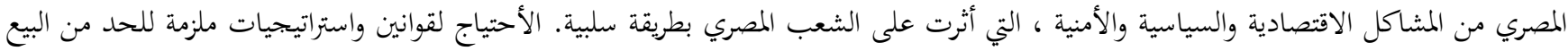

$$
\begin{aligned}
& \text { الغير مقنن للأدوية والمواد المستخدمة في التنظيف مع الحدل من التداول للمواد المخدرة. } \\
& \text { r قسم الطب الثرعي و السموم - كلية الطب - مستشفيات جامعة عين شمس مئ }
\end{aligned}
$$

